\title{
Appropriation, Rewriting and Alienation: A Postcolonial Critique of Mulan
}

\author{
Cheng Yali ${ }^{1}, \&$ Chen Kaiju ${ }^{2}$ \\ ${ }^{1}$ School of English for International Business, Guangdong University of Foreign Studies, Guangzhou, China (PRC) \\ ${ }^{2}$ Center of Business Culture and Philosophy of Culture, Institute of Hermeneutics, Guangdong University of Foreign \\ Studies; Institute of Advanced Studies, University of Chinese Academy of Social Sciences, Guangzhou, China (PRC) \\ Correspondence: Chen Kaiju, Center of Business Culture and Philosophy of Culture, Institute of Hermeneutics, \\ Guangdong University of Foreign Studies; Institute of Advanced Studies, University of Chinese Academy of Social \\ Sciences, Guangzhou, China (PRC).
}

Received: March 30, 2021

doi:10.11114/ijsss.v9i3.5226
Accepted: April 25, $2021 \quad$ Available online: April 28, 2021

URL: https://doi.org/10.11114/ijsss.v9i3.5226

\begin{abstract}
Released in September, 2020, Mulan, a live-action film starring Liu Yifei, was adapted by Disney from the Ballad of Mulan ${ }^{1}$. The film was produced from its animated version Mulan (1998) which hit global box office amounting to 304 million with marvelous reputation. However, the live-action movie Mulan did not continue the brilliant results of the previous work. Instead, Mulan (2020) disappointed most Chinese audience ${ }^{2}$ because historical facts and cultural values about Mulan were excessively appropriated, rewritten and alienated. Applying theories of Postcolonialism, this essay analyzes the live-action movie Mulan revealing the ethnocentric abuse of the target culture as the "other": arbitrary appropriation, rewriting and distortion of its historical events and traditional values. Also, theories of popular culture will be used to analyze the cultural industry strategies applied in this unsuccessful film.
\end{abstract}

Keywords: postcolonialism, popular culture, appropriation, alienation, otherness

\section{Preamble}

In Chinese literature, Hua Mulan is a loyal, filial, brave, modest and beautiful heroine. She lived in a period when the Huns were invading Central China from the North. The Emperor of China was forced to conscript a large army to repel the invasion of the Huns led by the ruthless Shan-Yu. Thus, the imperial decree went out to each household in the land to contribute one male member to the army. Since the Hua family only had a daughter, the honor of serving the mother country fell to Mulan's ageing and ailing father ${ }^{3}$, who had already served his country with honor. Mulan saw a chance to save her father from further service and to restore honor to herself (She lost her face on the match-making), so she disguised herself as a man and headed off to join the army (Peng, 2005). During the army period, Mulan was more courageous and loyal than men. The secret of her female sex was kept for twelve years. When she retired and returned home, Mulan's companions were surprised at her real and beautiful image: "We have been together with Mulan for twelve years, but never knew Mulan is a lady." Moreover, although Mulan attained fabulous glory and honor, she refused any reward, which showed her indifference to fame and fortune. In China, the Ballad of Mulan emphasized the national spirit of bravely resisting enemies without fear and the virtue of Confucianism about filial piety and loyalty. Therefore, Hua Mulan is an excellent example praised by folks as well.

It is evident that the story of Hua Mulan not only embodies marvelous qualities, but also provides abundant and available cultural resources for people at home and abroad. In China, the story of Hua Mulan has been adapted to TV drama $^{4}$, the living theatre ${ }^{5}$ Henan Opera ${ }^{6}$ and songs. ${ }^{7}$ Almost all Chinese people are familiar with Mulan because the

\footnotetext{
${ }^{1}$ the Ballad of Mulan (Chinese: 木兰辞; pinyin: Mù lán cí), a famous folk song of the Northern Dynasty in China.

${ }^{2}$ The investment in the live-action film Mulan is as high as US\$200 million (about 1.4 billion RMB). As a result, the global box office is less than US\$70 million. Also, the score in Douban is only 5.0 points. (the full mark is 10 .)

Sources:https://new.qq.com/rain/a/20201102A0J6EO00,https://movie.douban.com/subject/26357307/

${ }^{3}$ Mulan's father, Hua Zhou, with leg disability, is the only male member in the family.

${ }^{4}$ There are five versions of TV drama about Mulan: Hua Mulan (1996, played by Shi Aihong), Overwhelming Hua Mulan
} 
story of Mulan is incorporated as a compulsory text into national middle schools' mandarin textbook.

In addition to its popularity in China, the story of Mulan prevails abroad as well. It goes without saying that film is an unnegligible discourse in the configuration of knowledge and constructing power relations in the modern and postmodern world. A good case in point is the Disney animated film (Peng, 2005). In 1998, Disney Feature Animation released Mulan, which was meant to mark a departure from the studio's previous princesses and modes of storytelling. With great popularity, Mulan (1998) became a box-office success raking in $\$ 304$ million in the global box office in 1998 (Pomerantz, 2015). From then on, Disney attempted to rewrite a live-action movie Mulan in order to make profits from the target market. Twenty-two years later, the live-action movie Mulan came into being, which was starring by Liu Yifei $^{8}$ and directed by Niki Caro ${ }^{9}$. However, the live-action movie Mulan did not continue the brilliant results of the previous work. Instead, Mulan (2020) disappointed most Chinese audience. According to the market performance report in recent years, the quality and reputation of Disney animated live-action movies are mediocre, even if the box office varies immensely. If the movie can be loyal to the animated film and successfully restore the charm of the old work, there is no problem in making a fortune. For example, the global box office of Beauty and the Beast, Aladdin and The Lion King have successfully exceeded one billion dollars. However, compared with its animated version, the live-action movie Mulan was rewritten. For instance, the previous scenes of singing and dancing were cancelled, a large number of wars and action scenes were added, and the original carnival theme became an adventurous action movie. These rewritings have rated Mulan (2020) as "PG-13"10, becoming the first PG-13 live-action movie in Disney's history.

\section{Relevant Studies on Mulan}

In the past two decades, there are numerous prevalent scholars studying Mulan adapted by Disney but most of them concentrate on the animated film Mulan rather than the new live-action version. For instance, Peng Baoliang (2005) studied Mulan (1998) and other Disney movies to show representations of "Otherness" in Disney animated films. This study is an interdisciplinary critique of some of the typical but negligible representations of "Otherness" employed by the Disney Studio, for the purpose of exposing and verifying the fact that Disney programs, "clean and healthy and innocent" as they are frequently acclaimed, exercise manipulation and control more easily and conveniently than other forms of discourse.

Also, Michelle Anya Anjirbag (2018), she used views of coloniality to explore how the legacy of coloniality can still be seen embedded in the framing of Mulan (1998) despite the studio's stated intentions towards diversity and multiculturalism. Then she described that the animation style itself is utilized to convey a sense of otherness.

Until 2020, studies on Mulan did not come to an end. Jin Yunfei (2020) analyzed that how Mulan (1998) reflected the impact and integration of Chinese and western cultures. Her conclusion is that the western feminist thoughts and prevailing individualism are integrated into the animation, and the Confucian loyalty and filial piety in China are adapted into themes suitable for the Hollywood context.

One of the most important studies on the live-action movie Mulan is from Xu Qingli and Shi Ying (2020). They studied the live-action Mulan from the perspective of female gender identity and argued that all changes in Mulan (2020) contributed to building a more independent female identity in the modern world, concluding that this adapted version of Mulan will push women to be engaged in social fairs and take more social responsibilities, finally reflecting more independent gender identity of females.

Compared with the previous researches on Mulan, this study focus on the live-action film Mulan (2020), removes the perspective of feminism and individualism but continues the postcolonial viewpoints, carrying on the critique of the new Mulan (2020) by analyzing the appropriation, rewriting and alienation shown in the live-action movie. But the

(1996, played by Yang Lijing), A Tough Side of A Lady (1998, played by Chen Miaoying), Hua Mulan (1998, played by Anita Yuen and 2011, played by Yao Chen)

${ }^{5}$ The living theatre Hua Mulan (2020) is performed by Xi'An Performing Arts Group.

${ }^{6}$ Henan Opera (豫剧)is one of traditional operas originated from the middle of China. Hua Mulan is one of masterpieces in Henan Opera.

${ }^{7}$ Songs adapted from the story of Mulan abound, and the names of these songs are all the same. For instance, Hua Mulan sung by Zhang Manli (2015), by Angel Girls (2012) and by Ye Bei. (1998)

${ }^{8}$ Liu Yifei: (1987---) Popular Chinese actress, the Most Beautiful Person of the Year (2017 Fashion COSMO), Weibo Goddess of the Year in Sina Weibo Night. (2019)

${ }^{9}$ Niki Caro (1967---): New Zealand director, screenwriter and producer

${ }^{10} \mathrm{~A}$ movie rated as PG-13 means that to watch the film, children under 13 need to be accompanied by their parents. 
difference is that the study also covers the perspective of popular culture, further analyzing the excessive mass carnival and Disney's cultural industry strategies.

\subsection{Related Theories of Postcolonialism}

In the field of cultural studies, especially popular culture, postcolonialism is not an unfamiliar concept anymore. Compared with colonialism before the end of World War II, postcolonialism no longer focuses on war aggression, but shifts its focus to studying the East and the West. With the wave of globalization, cultural colonization spreads to all parts of the world with the strong economic strength of western developed countries. Although the definition of postcolonialism is still controversial and ambiguous, its rough outline can be found according to the specific expositions from relevant experts. Edward W. Said (1995) is best known for describing and critiquing "Orientalism"; what he perceived as a constellation of false assumptions underlying Western attitudes toward the East. Orientalism contains three meanings: First, it is a subject of learning, including all writing, teaching and research about the East; second, it refers to a style of thinking based on the ontology and epistemology between the East and the West; third, it refers to a style in which the West controls, rules, and constructs and exerts power in the East. Under the description of Orientalism, Europeans are rational, evolved, morally noble, mature, normal, and logical. On the contrary, oriental people are irrational, backward, savage, naive, illogical and mysterious (Mao, 2002). Said believes that the East is the silent otherness in the Western colonial discourse, and it is the subject of discipline without subjectivity. Elleke Boehmer (1998) defaulted that cultural hegemony, as an important part of western postcolonialism, has been repeatedly used in modern American mainstream popular cultural works.

\section{Critical Analysis of Mulan}

Different from the animated Mulan (1998) with globally high box office and pleasant feedback, in China, the live-action version Mulan (2020) was far away from audience's expectation and failed in both box office and feedback. ${ }^{11}$ One viewer from Douban Films remarked, that he found the film strange, saying, "only foreigners could make this kind of film. It wasn't like watching the Chinese story of Mulan." ${ }^{2}$ Another viewer from IMDb ${ }^{13}$ commented that "This is probably the worst movie I have seen in the past two years. And mind that Mulan still is one of my favourite cartoon movie, so that's quite something to achieve."14 Similar comments abounded on the Internet after the release of Mulan (2020). Why did the live-action version Mulan disappoint most Chinese audiences? Next, the reason will be analyzed from the rewriting, arbitrary appropriation and alienation of historical events and traditional values about original Mulan.

\subsection{Appropriation and Rewriting Embodied in Mulan (2020)}

According to James O. Young (2008), cultural appropriation refers to "A culture uses things from other cultures." That' to say, cultural appropriation is an act of taking or using things from a culture that is not your own, especially without showing that you respect or understand it. Young also divided the types of cultural appropriation into object appropriation, content appropriation, style appropriation, motif appropriation, and subject appropriation. In Mulan (2020), a host of rewritings have illustrated motif appropriation. It is a kind of deviated and partial appropriation, which is neither to reproduce nor represent another culture. The key word of motif appropriation is productive reception. The focus is not to preserve the original culture, but to display its own culture and understanding. For instance, the building where Mulan lives in the movie is Hakka round house ${ }^{15}$.The rewriting of building obviously conveys cultural mistakes both in time and space ${ }^{16}$. Worse still, when Mulan goes to see the matchmaker, her image is entirely a collection of the multicultural appropriation. (See Picture 1 below.)

\footnotetext{
${ }^{11}$ Source: https://www.sohu.com/a/417757027_120707218

${ }^{12}$ Source: https://movie.douban.com/subject/26357307/

${ }^{13}$ IMDb: the abbreviation of "Internet Movie Database"

${ }^{14}$ Source: https://zhuanlan.zhihu.com/p/228247448

${ }^{15}$ Hakka round house: Originally built in the Tang and Song dynasties (From the beginning of the 7th century to the end of the 13th century.) and flourished in the Ming and Qing dynasties. (Ming Dynasty: 1368 A.D.-1644 A.D. Qing Dynasty: 1644 A.D. - 1912 A.D.) The house combines the ancient and simple relics of the Central Plains and the regional characteristics of southern culture. It is one of the five major residential buildings in China.

${ }^{16}$ According to the original record, Mulan lives in Yu City. (in today's Henan Province, in the middle of China) And in the Ballad of Mulan, Mulan lives in the Northern Dynasty in Chinese history. (386 A.D.-581 A.D.)
} 


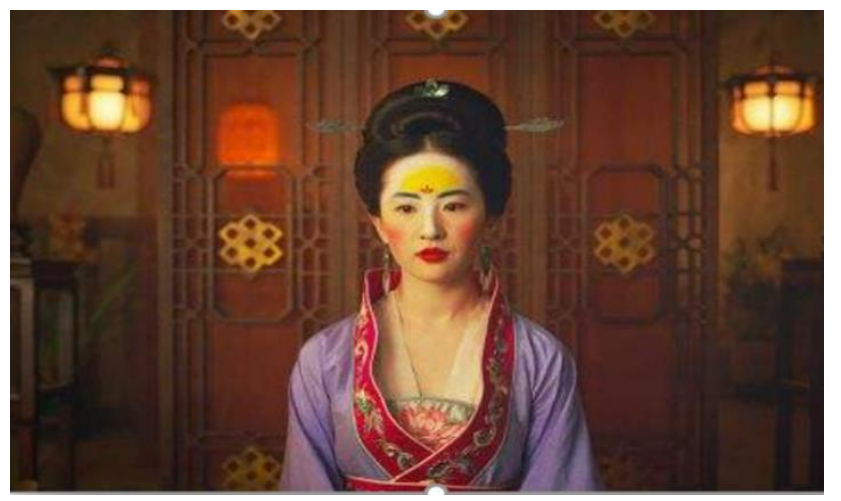

Picture 1. the image of Mulan when she goes to see the matchmaker

source: the live action movie Mulan (2020)

As is shown, Mulan's hairstyle is appropriated from the female bun ${ }^{17}$ in the Tang Dynasty; her makeup embezzles the characteristics of Japanese geisha, with purely white face but exaggerating blush on both cheeks; her clothing looks like Hanfu at first glance, but simultaneously with waist tightened and tube top style, which are inclined to costumes of the Tang Dynasty. Perhaps the most abused point is the red pattern painted on Mulan's forehead. Some audience deem the pattern immensely looks like the logo of one Chinese mobile phone brand. ${ }^{18}$ In accordance with its own understanding and rewriting, Disney presented a new hybrid Mulan by applying motif appropriation. The architecture and character dress in the live action film were largely deviated from the description about Mulan in traditional Chinese works.

There are still numerous examples of cultural appropriation with misleading understanding in Mulan (2020). The film's depictions of Chinese elements were stripped of context and embed historical inaccuracies such as the episode with the matchmaker and the presence of the Rourans ${ }^{19}$. Perhaps most importantly, Disney's iteration perpetuates orientalized stereotypes by conflating racial and gender perceptions, where the oriental other is both effeminate and irrational, and this depiction serves to motivate the conflict (Yin, 2014; Dundes \& Streiff , 2016; Dong 2011). They solidified oriental elements and images, mixed their comprehensible parts in the movie, and produced a result that deviated from historical facts and was absurd and ridiculous. The underlying assumption embedded in this process is that only the dominant (Western) culture can be universally understood, and that the values of that culture are the default standard to be imposed on the rest of the world. Such domination under the guise of appropriation and rewriting also "imposes the perspectives or values of the dominant on the dominated cultures, and does not allow them to use their own perspectives or facts," reinforcing the construct of the dominated group as "other" and the dominant group as the natural and standard "Self" (Yin, 2014).

The process of appropriating Chinese legends by western cultural media is a dialogue between two cultures. In this dialogue, the American culture obviously has the absolute power to speak by virtue of its economic and technological advantages. Disney, the mainstream media, has essentialized and categorized the local culture carried by ancient Chinese legends, degraded it into a series of oriental codes, dispelled the strong support of local culture, and injected stubborn ethnocentric cultural elements, and then according to their narrative logic, they reconstructed an unrecognizable eastern mythology, thus integrating the material of China's marginal culture into the strong Western culture, becoming a new member of popular culture, and making it a tool for expressing Western power discourse. This leads to the marginalization of local culture, identity misplacement, identity rewriting and even identity loss.

Cultural appropriation, as a matter of fact, is an effective and fabulous way to show cultural diversity and learn about other cultures when it is correctly used. However, if cultural misappropriation or even cultural plagiarism is done for a certain profit or cultural hegemony, disrespecting the history of the original culture and distorting the facts of the original culture, it is not desirable at this time, and it will further deepen the negative impact of postcolonialism on cultural development.

\footnotetext{
${ }^{17}$ the female bun: Chinese:女士发䯽, refers to fixing the whole hair with hairpins after panning it. It is a popular female hairstyle in the Tang Dynasty.

${ }^{18}$ News source: https://new.qq.com/omn/20190708/20190708A0A6HX00.html?pc?

${ }^{19}$ Rourans: Invaders from the north of China
} 


\subsection{Alienation of Chinese Culture as "Other"}

Said (1995) sharply pointed out that the "orientalism" expressed by Westerners is based on their own ideology and behavioral norms, thus the true culture of the East has been obscured by Westerners. The West has been condescending to define the East with Western epistemology, and maintains its own and the other, the center and the marginal ruling model with hegemonic discourse. Homi K. Bhabha (1994) pointed out that the colonial discourse aims to interpret the colonists as "Other" based on the difference of race, and the purpose is to provide a basis for the colonial conquest by force.

The representation of the "otherness" has never been innocent, and it is impossible to achieve ideological impartiality(Hall, 1995). In the process of reproducing the "otherness" in the adaptation of the live-action movie Mulan, Disney has distorted and otherized the original story, replacing the values of Chinese local culture with the individualistic values of American mainstream culture, thereby misplaced the identity of the reproduced objects. The integration, colonization and marginalization of culture are the political mirror images set by the Western ideology to control the East. That's to say, otherness refers that westerners regard the non-western world outside as "the other" and put them in diametrical opposition, actually implying the ideology of west-centralism.

The phenomenon of otherness used by Disney is apparently shown in Mulan, which can be easily found in differences between the original ballad and the rewritten movie. In the Ballad of Mulan, Hua Mulan was written as a responsible and filial daughter, in which case, she disguised herself to take the place of her ailing father in the army out of a sense of filial duty — and this was the key part—with her parents' blessing. The concealment of her sex was kept for twelve years after which she retired, refusing any reward. In China, the Ballad of Mulan emphasized the national spirit of bravely resisting enemies without fear and the traditional virtue of filial piety and loyalty. Hua Mulan is an excellent example praised by folks as well.

On the contrary, Disney's version emphasized individualism and personality with Mulan's character, increased the magic of animals (phoenix and eagle), and used her secret of sex as a conspiracy to make her succumb to the army. ${ }^{20}$ More ridiculously, in the movie, there exists a witch called Xianniang (Starring Gong Li) who becomes a counterpart to Mulan. Both of them have the power of "chi". (See Picture 2) The power of "chi", refers to the Chinese character "气”. In Mulan, the power of "chi" is a kind of superpower which is feared and rejected by sundry people. When they defeat enemies or overcome difficulties, movie producers ascribed their abilities into the power of "chi". In addition, when the imperial city was seriously invaded and attacked by the witch, the emperor (Starring Jet Li) called her power of "chi" as "dark magic". (See Picture 3) From the perspective of western judgement, the power of chi can be equivalent to the dangerous and frightening "dark magic", which converts Chinese culture into a negative mythology without appropriate understanding.

It is not difficult to conclude that some rewritings have been alienated, distorted, mythologized and otherized. The change between ballads and movies reveals a process in which Chinese cultural values are selectively disposed and replaced by Western ideologies, while strengthening the sense of ethnocentric otherness and racial/cultural hierarchy. These changes altered the social and cultural values of the ballad in such a way that it altered the cultural currency of the narrative while reinforcing negative stereotypes and orientalizing of Chinese people (Anjirbag, 2018).

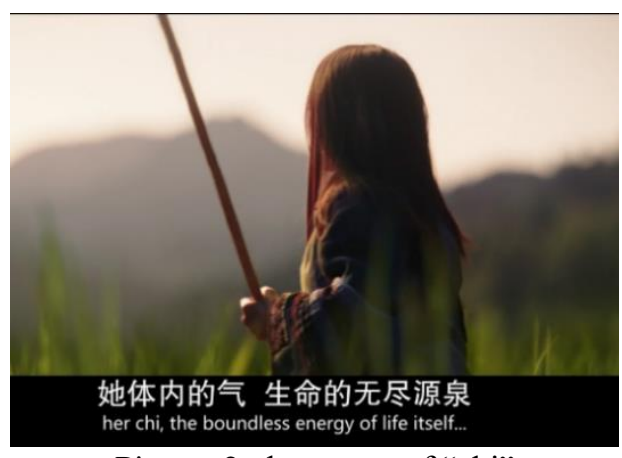

Picture 2. the power of "chi"

source: the live-action movie Mulan (2020)

${ }^{20}$ In the movie, penalties of dishonesty are expulsion and disgrace for oneself, for his family and even for his country. 


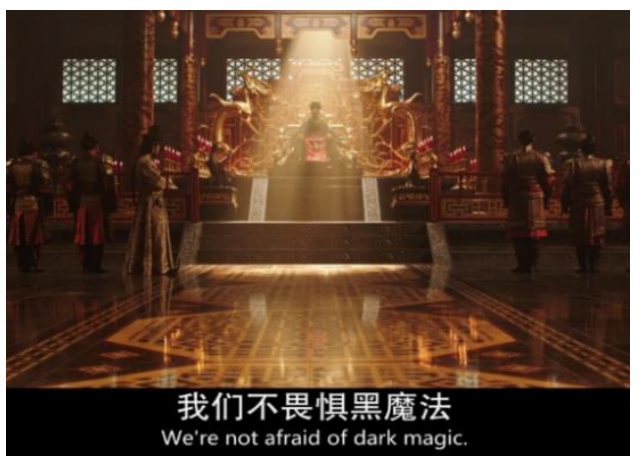

Picture 3. "chi" is regarded as "dark magic"

source: the live-action movie Mulan (2020)

\section{Analysis of Mulan from the Perspective of Popular Culture}

With what has been discussed above, we mainly criticize the embodiment of otherness (rewriting and distortion) and appropriation in the live-action movie Mulan by using postcolonial theories. Next, opinions of popular culture will be used to analyze the excessive mass carnival and cultural industry strategies.

\subsection{Popular Culture}

The rapid advancement of science and technology has urged the mass media to continuously expand new cultural horizons and cultural space in order to adapt to its own development, and to provide audience with abundant cultural works (Wang, 2020). It can be said that mass media plays a pivotal role in cultivating, inducing, stimulating, and expanding the consumer desires of individuals, and in the process of creating or rewriting popular culture.

In China, popular culture, it was a foreign borrowed concept, and only in the English language environment can we understand the concept better. In the English context, mass culture, popular culture, and similar folk culture can all be translated as "popular culture", but the meanings of these three are different. Mass culture is a concept closely related to mass media. With the emergence of mass media such as radio and television, mass culture has gradually emerged and spread. Popular songs, movies, TV dramas, and humorous jokes can all be part of mass culture. Modern technology allows mass culture to be mass-produced, and producers can obtain economic benefits. From a political point of view, mass culture is a top-down culture. The mass did not consciously choose this culture, but were interfered by the external environment and passively accepted this culture. Popular culture is a culture with a longer history. It was born before newspapers, radio, and television. Even in the case of late capitalist society where media culture dominates, popular culture can still be independent through publications. Therefore, popular culture is a broader culture. Popular culture is a concept corresponding to high culture. Its characteristic is easy to understand. Its appearance makes culture no longer serious and mysterious. Instead, it goes to ordinary people and becomes an important part of daily life. Folk culture, its original meaning is "folk custom and traditional folk", while folk culture refers to culture represented by folk stories, folk songs, and folk opera. Folk culture is a bottom-up culture. It is originated from the folks, mostly based on the lives of ordinary people. It is an expression of ordinary people's life experience and feelings. Therefore, it is opposed to the culture of the ruling class. In terms of scope, folk culture is an integral part of popular culture, but it has its own unique meaning and expression. In summary, popular culture is a culture with a wider scope and a longer history, while mass culture is a direct result of the rapid development of modern technology.

Popular culture has the characteristics of being easy to understand, widely spread, and prevailing among people (Chen, 2004). In other words, popular culture tends to individuals' resonance and carnival. Bakhtin (1984) put forward the theory of carnival in Problems of Dostoevsky's poetics which is based on the free form of folk carnival. Carnival enjoys a long history as a universal cultural phenomenon. As early as in ancient Greece and Rome, carnival played an important role in popular life, and it penetrated into various religious and sacrificial activities. In the Middle Ages, all kinds of folk literature, event ceremonies and carnival celebrations all had the characteristics of contradiction and opposition between tradition and the carnival system. During the Renaissance, all activities took place in the form of a carnival. In the latter half of the 17th century, carnival life gradually declined and even worsened. But in the postmodern era, "carnival and postmodernism" once again returned to the mainstream vision. The integration of culture represented by carnival and popular culture has brought the carnival and humor elements of folk culture into the ranks of popular culture (Liu, 2020).

In terms of films, for instance, attracting the audience's attention and stimulating their excitement are the prerequisites 
for carnival. And then the purpose of carnival is to take advantage of these characteristics of popular culture and finally to obtain a huge number of profits.

\subsection{Excessive Mass Carnival: Things Will be Reserved}

The live-action film Mulan was remade from its 1998's cartoon version whose box office globally grossed 304 million with marvelous reputation. But the live-action movie Mulan did not continue the brilliant results of the previous work whether in box office or reputations from audience. It could not be ignored that Disney has made great efforts to select the actress to act Mulan. At last, Liu Yifei was successfully selected as the heroine. When Niki Caro, the director of this live-action Mulan was interviewed why she chose Liu Yifei to act Mulan, she said, "She's incredibly beautiful, but she's also really handsome. As a guy, she fits in." (Xu \& Ying, 2020). For Mulan has the features of a woman and a man, she has to be able to excellently finish the martial arts plots in the movie and to speak frequent English with princess temperament. The most significant reason for choosing Liu Yifei is that her considerable reputation in China and even around the world is so profitable that it can help this movie to attract enough heat and attention. After all, Disney intended to make use of its splendid cast to create stunning effects and eventually to make a big fortune in the global film markets. In the movie, for instance, the emperor is played by Jet $\mathrm{Li}$; the army general by Donnie Yen; the witch Xianniang by Gong Li. All of them have pivotal positions in the field of Chinese film. Disney did this to create a blockbuster effect of the experience, which would arouse public carnival. However, despite the huge cast, the far-fetched plots and excessive mass carnival made the result unsatisfactory.

The use of verbal humor must control the scale of attack, and if it is overrun, the humorous effect may be lost (Ma \& Chen, 2009). In addition to the strong cast, in Mulan, Disney movie producers tries to show a sense of humor. However, the form and contents are immensely alienated, making audience especially Chinese audience feel weird and embarrassed. Here is an example in the live-action film Mulan, a conversation between soldiers about their ideal types of women:

Soldier A: I like my women buxom with strong, wide hips.

Soldier B: I like kissing women with cherry red lips.

Soldier C: I don't care what she looks like. I care what she cooks like.

(Everyone burst into laughter with Hahahaha... except Mulan.)

Honghui (asks Mulan): What is your ideal woman?

Mulan: $\quad$ My ideal woman is courageous. (Two soldier laugh out loud) And she has a sense of humor. (Two soldier laugh louder) She's also smart. (with laughter again)

Soldier B: Well, what does she look like?

Mulan: That's not the point.

Soldier A: Courageous, funny, smart...Hua Jun (Mulan) is not describing a woman. He's describing me. Hahaha....

In the conversation, a group of soldiers are talking about women. The words they use such as "buxom", "hips", "kissing", "lips" can not help but let people think of the domain of love or sex, which is quite suspected of implanting alienated culture. Back to reality, in ancient China, the figure and image of women were hardly talked about explicitly, especially in public. Therefore, such content is incompatible to the original cultures and values. What's worse, soldiers laugh out loud during the conversation when Mulan talks about her ideal woman, which implies a vulgar and impolite attitude towards Mulan. This also looks like an embarrassing scene directed and acted by a clown himself. The rewriting of this plot did not achieve an effective sense of humor, but increased the audience's confusion and even misunderstanding.

It is not tough to see that the Disney filmmakers wanted to add attractive and shining points to Mulan through the luxurious cast and humorous film plots, aiming to generate mass carnival. But facts have proved that in order to achieve good results, we need to respect the core values and historical facts of the original culture. Otherwise, things will be reversed.

\subsection{Strategies Applied by Disney Movies}

Disney, as a well-renowned industrial giant, although its main business product is cultural output, it will eventually strive to survive in the capital market by continuously making profits. Profit-seeking strategies determine the utilitarian nature of capital and the maximization of short-term benefits. It mostly cares about benefits. The capital market is keen to chase the restructure of wealthy effects far more than industrial integration. However, cultural industry is different from manufacturing industry. Its input and output require a certain cycle. At the same time, it has the dual attributes of industry and culture. Cross-border capital mergers and acquisitions of the cultural industry not only need to break 
industry barriers, and achieve business philosophy and cultural compatibility, but also it is necessary to follow the developmental law and value orientation of cultural products themselves.

In the live-action film Mulan, we can see Disney producers have made use of a large number of Chinese elements to attract Chinese audience's attention. In the final analysis, the media is keen to present audience culture, because attracting the audience means occupying the market, possessing potential benefits. The most essential purpose for Disney is to earn considerable box office all over the world especially in China. That's why China is the first country to release this live-action movie, which is an uncommon style of Disney. Super movie stars will have a positive impact on the profitability of medium-budget movies, but have little effect on the profitability of high-cost movies. The accumulation of stars will not bring better results. (Sedgwick \& Pokorny, 1998) However, Disney invited numerous Chinese stars to act this high-budget movie, in particular those well-known and popular actors and actresses. In addition, Chinese filming locations abound in the movie; and Chinese elements are reflected even in some details such as the red couplets $^{21}$ at the gate of Mulan's house, the spirits curved on Mulan's sword: loyal, brave and true, as well as the phoenix representing an outstanding woman (Mulan). All these measures are to motivate more audience to watch this movie. Ridiculously, however, many Chinese elements shown in the film are largely misappropriated from various Chinese and even foreign cultural sources, thus, finally, they become ambiguous combinations, confusing and misleading the audience.

The first official trailer of the live-action movie Mulan was released during the interval of the Women's World Cup on July 7, 2019. On that day, it was the final between the United States and Netherlands to compete for the women's football world championship. Thousands of fans saw the sudden "Mulan" trailer on the live screen. The red outfits of an Eastern beauty, and the brave and unrestrained Hua Mulan immediately ignited spectators' excitement inside and outside the stadium. 175 million views on the Internet were generated globally within a day. ${ }^{22}$ The release of the live-action movie Mulan has become a hot issue from then on. It is noteworthy that his adapted work is not only the first live-action film with the theme of Chinese legends in the "Disney Princess Series", but also the first Disney princess acted by a Chinese actor. In particular, among the 14 princesses in the "Disney Princess Series" launched by Disney so far, Hua Mulan is the only princess who does not rely on princess birth, does not rely on marriage to the royal family, but on her own growth, power and self-recognition. Personal charm and comprehensive strength were awarded the title of "Princess". Therefore, it is not exaggerating to say that Hua Mulan from China has rewritten and expanded the connotation of the "Disney Princess" image, whose purpose is to create billions of dollars in value and shaped the acceptance of global audience.

\section{Conclusion}

The live-action movie Mulan is a typical otherized movie because historical facts and cultural values about Mulan were conspicuously appropriated, rewritten and distorted. The rewriting of the live-action movie Mulan has greatly weakened the original story, failing to convey the true historical and cultural facts and disappointing Chinese local audience. Despite using lots of Chinese elements as movie's trump card to earn box office profits from the target market, results did not satisfy both audience and the filmmakers. Homi K. Bhabha's sharp statement is worthy of warning: "All the results of ignoring cultural differences, all the practices of smoothing out the position of the minority discourse, the final result may be to copy the politics and culture of imperialism, making global culture lose its differences and become a flat module. That will be the end of human culture "(Bhabha, 1994). For popular culture, while pursuing profits, it is more important to respect cultural diversity and differences and maintain an equal and open attitude towards other cultures.

\section{References}

Anjirbag, M. A. (2018). Mulan and Moana: Embedded Coloniality and the Search for Authenticity in Disney Animated Film. Social Sciences, 7(11), 1-15. https://doi.org/10.3390/socsci7110230

Bakhtin, M. M. (1984). Characteristic of genre. In Problems of Dostoevsky's poetics, ed. and trans. C. Emerson, Minneapolis: University of Minnesota Press. 80-101. https://doi.org/10.5749/j.ctt22727z1

Bhabha, H. K. (1994). The Location of Culture. London: Rout-ledge.

Boehmer, E. (1998). Colonial and Postcolonial Literature. Trans. Sheng, N. \& Han M. Z., Shenyang: Liaoning Education Press; Oxford UP.

\footnotetext{
${ }^{21}$ The contents on the red couplets are cited from the Romance of west Chamber, a famous literature in the Yuan Dynasty (1271 AD.---1368AD.) This detail is also a cultural misappropriation in the live action movie Mulan, for Mulan was living in the Northern Dynasty (386AD. - 581 AD.) rather than the Yuan Dynasty.

${ }^{22}$ Source: http://content.mtime.com/news/1594822
} 
Chen, K. J. (2004). Clingingness and Subversion of Popular Culture--An Analysis of the Chinese Comic Sketch the Red Broomcorn Models. Jiangxi Social Sciences, 181-184.

Dong, L. (2011). Mulan's Legend and Legacy in China and the United States. Philadelphia: Temple UP. https://doi.org/10.3390/soc6040035

Dundes, L., \& Streiff, M. (2016). Reel Royal Diversity? The Glass Ceiling in Disney's Mulan and Princess and the Frog. Societies-Open Access Journal of Sociology.

Hall, S., \& Gebeni, B. (1995). The West and the Rest: Discourse and Power. Formation of Modernity. Cambridge: Polity Press. 293-294.

Jin. Y. F. (2020). Hua Mulan: An Analysis of the Conflicts and Combination of Chinese and Western Cultural Images. Modern and Ancient Literary Creation, 27, 59-60.

Liu, X. (2020). Cultural Interpretation of Online Variety Show "Youth With You II" from the Perspective of Carnival Theory. RADIO \& TV JOURNAL, 11, 36-37.

Ma, X., \& Chen, K. J. (2009). Research on Cultural Strategy of Utterance Humor. Jianghan Tribune, 09, 130-132.

Mao, S. H., \& Yang, S. (2002). Reimagination of Pocahontas in popular Disney film Pocahontas with a focus on ethnicity, articulation and cultural appropriation. Comparative Literature in China, 02, 45-56.

Peng, B. L. (2005). Representations of "Otherness" in Disney Animated Films. [D]. Guangzhou: Guangdong University of Foreign Studies, 1-219

Pomerantz, D. (2015). Live Action 'Mulan' in the Works as Disney Follows the Money. Forbes, March 30.

Said, E. W. (1995), Orientalism. Penguin Books Ltd., London.

Sedgwick, J., \& Pokorny, M. (1998). Movie Stars and the Distribution of Financially Successful Films in the Motion Picture Industry. Journal of Cultural Economics, 4, 319-323.

Wang, Z. H. (2020). Traditional Media and New Media Communication from the Perspective of Popular Culture. China Newspaper Industry, 20, 32-33.

Xu, Q. L., \& Shi, Y. (2020). Female Gender Identity in the Adaptation of Disney Live-action Film Mulan. English Language, Literature \& Culture, 5(3), 112-115. https://doi.org/10.11648/j.ellc.20200503.16

Yin, J. (2014). Popular Culture and Public Imaginary: Disney vs. Chinese Stories of Mulan. The Global Intercultural Communication Reader, 285-289.

Young, J. O. (2008). Cultural Appropriation and the Arts. Chichester: Wiley-Blackwell. https://doi.org/10.1002/9780470694190

\section{Copyrights}

Copyright for this article is retained by the author(s), with first publication rights granted to the journal.

This is an open-access article distributed under the terms and conditions of the Creative Commons Attribution license which permits unrestricted use, distribution, and reproduction in any medium, provided the original work is properly cited. 